\title{
The Effect of Parathyroid Hormones on Hair Follicle Physiology: Implications for Treatment of Chemotherapy-Induced Alopecia
}

\author{
Anna Skrok ${ }^{a}$ Tomasz Bednarczuk $^{b}$ Agata Skwarek $^{b}$ Michał Popow $^{b}$ \\ Lidia Rudnicka ${ }^{a}$ Małgorzata Olszewska ${ }^{a}$ \\ Departments of ${ }^{\mathrm{a}}$ Dermatology and ${ }^{\mathrm{b}}$ Endocrinology, Medical University of Warsaw, Warsaw, Poland
}

\section{Key Words}

Chemotherapy-induced alopecia · Hair dermoscopy . Hair loss · Hypoparathyroidism · Hyperparathyroidism . Parathyroid hormone $\cdot$ Parathyroid hormone-related protein · Trichoscopy

\begin{abstract}
Parathyroid hormone (PTH) and parathyroid hormone-related protein (PTHrP) influence hair follicles through paracrine and intracrine routes. There is significant evidence that PTH and PTHrP influence the proliferation and differentiation of hair follicle cells. The PTH/PTHrP receptor signalling plays an important role in the hair follicle cycle and may induce premature catagen-telogen transition. Transgenic mice with an overexpression or blockade (PTH/PTHrP receptor knockout mice) of PTHrP activity revealed impaired or increased hair growth, respectively. Some findings also suggest that PTHrP may additionally influence the hair cycle by inhibiting angiogenesis. Antagonists of the PTH/PTHrP receptor have been shown to stimulate proliferation of hair follicle cells and hair growth. A hair-stimulating effect of a PTH/PTHrP receptor antagonist applied topically to the skin has been observed in hairless mice, as well as in mice treated with cyclophosphamide. These data indicate that the PTH/PTHrP receptor may serve as a potential target for new (topical) hair growthstimulating drugs, especially for chemotherapy-induced alopecia.

(c) 2015 S. Karger AG, Basel
\end{abstract}

\section{Introduction}

Hair follicles are not only hormone-dependent structures, but they can also produce a variety of hormones acting in a paracrine, autocrine or intracrine manner, therefore causing changes directly in the skin and in hair biology [1-3]. Thus, hormones produced by the skin and the hair follicles may play an important role in maintaining or dysregulating hormonal homeostasis, in general. This endocrine function of the skin and hair follicles appears to be underestimated. Already, the expression of multiple numbers of hormones and their receptors has been discovered in hair follicles $[4,5]$. Hair follicles seem to be fascinating dermato-endocrinological units.

Among endocrine disorders which are important in hair biology, hyperandrogenism is best investigated $[6$, 7]. It has also been recently proven that thyroid abnormalities are strongly associated with hair growth [8]. There is a putative role of glucocorticosteroids and prolactin in hair biology $[9,10]$. The role of parathyroid hormone (PTH) and abnormalities of parathyroid gland function in hair growth remains not well understood.

Primary hyperparathyroidism is related to an increased activation of $\alpha_{1}$-hydroxylase and calcitriol synthesis. It leads to phosphate absorption in the gastrointestinal tract and phosphate reabsorption in the proximal tubules of the kidneys. A rising level of phosphates activates a negative feedback mechanism in the vitamin D and PTH axis. This

\section{KARGER 125}

2015 S. Karger AG, Base

$1660-5527 / 15 / 0284-0213 \$ 39.50 / 0$

E-Mail karger@karger.com

www.karger.com/spp
Małgorzata Olszewska, $\mathrm{MD}, \mathrm{PhD}$

Department of Dermatology, Medical University of Warsaw Koszykowa $82 \mathrm{~A}$

PL-02-008 Warsaw (Poland)

E-Mail malgorzata.olszewska@wum.edu.pl 
results in an increased ability to eliminate calcitriol by CYP24B1 (cytochrome P 450 family 24 subfamily B, one of the genes involved in the vitamin $\mathrm{D}$ metabolism pathway) $[11,12]$. PTH, an inhibitor of hair development, competes with calcitriol, which stimulates hair growth [13]. The final effects may vary among patients, and this must be taken into consideration when studying hair pathophysiology [14]. PTH, produced by the parathyroid gland, has been found to be expressed in the hair follicle, as well as its receptors [15]. It has been proven that PTH is another factor playing a role in the regulation of the hair growth cycle. An agonist of the receptor for $\mathrm{PTH}$, the parathyroid hormone-related protein (PTHrP), is also expressed in skin and hair follicles, regulating their proliferative activity. There is a significant body of evidence suggesting the potential role of parathyroid hormone receptor (PPR) ligands. It has been proven that agonists or antagonists of PPR can inhibit/promote hair growth [16]. Despite the potent role of PTH/PTHrP in hair growth modulation, there is still a lack of studies regarding parathyroid-related disorders. Also, general mucocutaneus manifestations of PTH-related disorders seem to be underevaluated, especially in non-familial cases of parathyroid disorders.

\section{Hair Follicle Morphology}

The development of the skin with its appendages is necessary for humans to create a well-functioning skin barrier [17]. The human pilosebaceous unit is a highly proliferating organ. This capability is crucial in understanding the role of its numerous dermato-endocrinological cross-actions [4]. The hair follicle is also a fascinating subject for molecular biologists, who find it to be a perfect model for studies. As knowledge broadens, the biology of the hair follicle seems to be more and more complicated. The follicular unit, which consists of the hair follicle, the sebaceous gland and the arrector pili muscle, is derived from epithelium and mesenchyme cell layers, which create different compartments of the hair unit with their own unique functions [18].

Hair follicle structure can be divided into two elements: a permanent superficial structure and non-permanent portion, known as the cycling region [19]. The line of that division lies below the hair follicle bulge region, so below the insertion point of the arrector pili muscle. The bulge region is in fact a part of the outer root sheath, and it has been proven to consist of stem cells [19]. A transient, cycling portion, including the hair bulb, is crucial for regenerative ability [19]. Rapid proliferation of cells in the bulb region (adjacent to the dermal papilla) during the anagen phase causes hair shaft and inner root sheath growth [20]. In accordance with that, damage of the dermal papilla results in an inability to provoke the regrowth of hair [21]. All compartments of the hair unit, including the epithelium of the follicle's outer and inner root sheaths, the bulge area, the dermal papilla, the matrix cells containing melanocytes, the surrounding nerves, sebaceous glands, vasculature and lymphoid cells, cross-act with each other and regulate the hair growth cycle [22]. Each of these various hair follicle compartments acts as a specific location of production and/or reception of diverse hormones impacting the hair growth cycle.

\section{Hair Growth Cycle}

Humans are born with approximately 2 million follicular units, and no new hair follicles are created after birth. It has been shown that the significant regenerative ability of hair depends on the hair growth cycle phenomenon [23].

The hair growth cycle consists of three main phases: anagen (growth phase), catagen (regression phase) and telogen (resting phase) [24]. Anagen is a phase of active proliferation resulting in hair growth. Catagen is related to cessation of protein and pigment production, involution of the hair follicle and restructuring of the extracellular matrix. In the third, resting phase, called telogen, the hair follicle regresses. Recently, it has also been shown that shedding is, in fact, an active process which differs from telogen. To distinguish the shedding phase, researchers have named this process the exogen phase [25]. It has been discovered that exogen refers to a proteolytic activity in the cells of the telogen shaft base. It is also known that this is connected to a loss of desmoglein 3 [26]. Kenogen is another stage of the hair cycle which can sometimes be observed. It occurs after shedding, when the empty hair follicles of the hair shaft can be observed and before the onset of new anagen. Clinically, it evokes a lack of hair coverage after shedding, and it is seen most frequently in androgenetic alopecia patients [27].

The hair follicle cycles go from anagen to telogen continuously, but a crucial and key target in this cycle seems to be the length of the growth phase. It must be noted that the length of anagen, which is also dependent on the body site location, determines the physical appearance of hair $[2,28]$.

Changes in the hair growth cycle often result in alopecia. However, it may be possible to promote the anagen phase to treat hair loss disorders. 
Table 1. The modulators of the hair cycle

\begin{tabular}{ll}
\hline Promoters of anagen & Inducers of premature catagen-telogen transition \\
\hline$\beta$-Catenin [90] & Brain-derived neurotrophic factor (BDNF) [101] \\
Fibroblast growth factor 2 (FGF-2) [91] & Bone morphogenetic protein 2 (BMP-2) [102] \\
Fibroblast growth factor 7 (FGF-7) [92] & Bone morphogentic protein 4 (BMP-4) [102] \\
Hepatocyte growth factor (HGF) [93] & Epidermal growth factor (EGF) [103] \\
Insulin-like growth factor 1 (IGF-1) [94] & Fibroblast growth factor 2 (FGF-2) [104] \\
Lymphoid enhancer-binding factor 1 (LEF-1) [95] & Fibroblast growth factor 5 (FGF-5) [105] \\
Macrophage-stimulating factor (MSP) [96] & Interleukin 1 (IL-1) [106] \\
Platelet-derived growth factor (PDGF) [97] & Interleukin 6 (IL-6) [107] \\
Sonic hedgehog (SHH) [94] & Interferon $\gamma($ IFN- $\gamma$ ) [108] \\
Transforming growth factor a (TGF- $\alpha$ ) [98] & Neurotrophin 3 (NT-3) [109] \\
Noggin (NOG) [99] & Oncostatin (OSM) [110] \\
Vascular endothelial growth factor (VEGF) [48] & Parathyroid hormone (PTH) [16] \\
WNTs [100] & Transforming growth factor $\beta_{1}\left(\right.$ TGF- $\left.\beta_{1}\right)[111]$ \\
& Transforming growth factor $\beta_{2}\left(\right.$ TGF- $\left.\beta_{2}\right)[112]$ \\
\hline
\end{tabular}

Additionally, the longer the telogen, the greater the chance of kenogen, resulting in the clinical presentation of lack of hair [1]. Conversely, factors shortening telogen and promoting anagen will decrease the percentage of kenogen hair follicles [29]. Factors and drugs elongating/ promoting anagen, as well as those reducing the duration of telogen, are the targets for researchers investigating hair growth disorder treatments.

Within recent years, the list of factors that have an impact on hair cycling and could be used as possible research targets has been constantly growing. The modulators of the hair cycle are grouped in table 1 [2].

As indicated above, PTH is one of the causative factors of a premature anagen-to-catagen/telogen transition [2]. Changes in the balance between anagen-promoting factors and factors inducing catagen (like PTH) result in hair growth dysregulation. All the regulatory factors are under investigation as potential hair growth promoters or inhibitors.

\section{Hormonal Impact on Hair Growth Cycle}

Hormones affect follicular mesenchymal-epithelial interactions: altering growing time, dermal papilla size, dermal papilla cell, keratinocyte and melanocyte activity [2]. A better understanding of these mechanisms should improve the treatment of poorly controlled hair disorders. Androgens are the most important regulators of human hair growth. Also, thyroid function abnormalities and poor nutrition are the factors leading to hair growth disruption [30-32]. Recently, scientific curiosity has led to the development of an intensely expanding amount of knowledge concerning other hormonal impacts on hair metabolism. Recently, the list of hormones, neurotransmitters and receptors expressed in the hair follicle, has been growing [33].

\section{The Role of PTH and PTHrP in Hair Cycling}

There is significant evidence that PTH and PTHrP influence the proliferation and differentiation processes of the epidermis and hair follicle (table 2). PTH is a polypeptide hormone secreted by the parathyroid glands, normally, as a response to serum calcium and phosphate levels [34]. PTHrP is in fact a polypeptide sharing $70 \%$ homology in the N-terminal fragment with PTH. It was first discovered in humoral hypercalcaemia of malignancy, as a protein produced by different tumours [35].

It has been proven that PTHrP and its $\mathrm{mRNA}$ are present in normal fetal and adult tissues, especially in organs with highly proliferating cells, such as bones, kidneys, the placenta, hair follicles and the skin [15]. The secretion of PTHrP in the skin was first identified over 20 years ago in human keratinocyte cultures [36]. Receptors for PTHrP and for PTH in the hair follicle have been localized in the dermal sheath and the dermal papilla of developing hair. Activation of PPR (receptors for PTH/PTHrP) in the hair follicle regulates the anagen-to-catagen transition of the hair cycle $[2,37]$.

It is well proven that the $\mathrm{PTH} / \mathrm{PTHrP}$ signalling influences proliferation and differentiation of mesenchymederived cell types. The current hypothesis suggests that $\mathrm{PTHrP}$ is released by epidermal cells and migrates to 
Table 2. Hormones/neurotransmitters and their receptors expressed in the hair follicle [4]

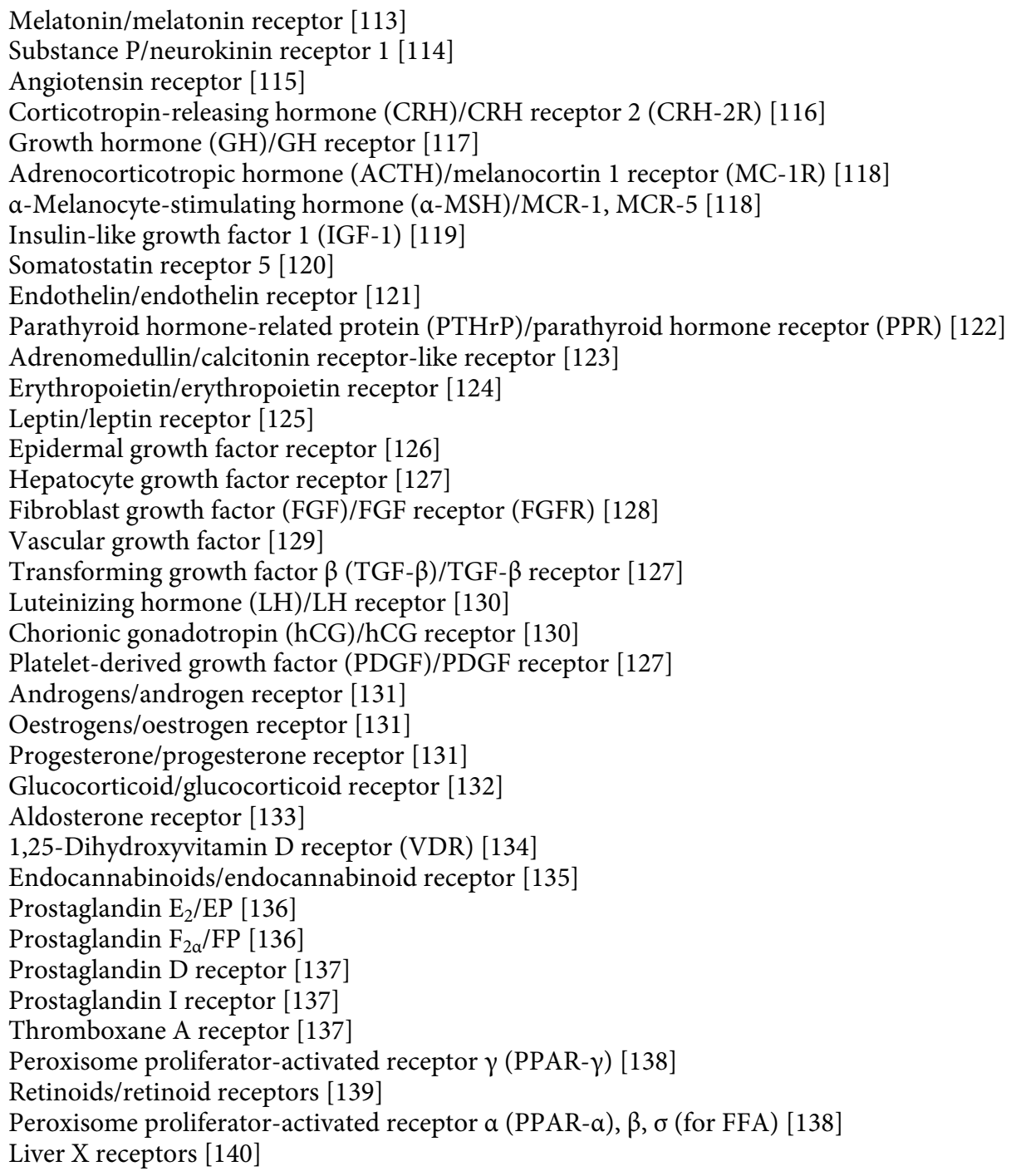

cross-act with the dermal portion, as these cells are equipped with PPR.

As PTHrP shows paracrine activity in various tissues, the model of receptor signalling (PPR) is then discussed. Two different types of PTH/PTHrP receptors - the classic (type $1 \mathrm{PPR}$ ) and the unconventional one - are speculated. The classic receptors for PTHrP and PTH are found to be expressed on human dermal fibroblasts [38], while a specific one is present on keratinocytes [39]. The receptor for PTH/PTHrP is a G-protein-coupled receptor which transduces the signal through adenylyl cyclase or phospholipase C second messenger pathways [40]. Surprisingly, in some tissues PPR has no effect on protein kinase $\mathrm{A}$ /protein kinase $\mathrm{C}$ pathways. However, in these cells, like in the dermal papilla, PPR signalling still alters proliferative functions through tyrosine phosphorylated protein [41].

The expression of PTH/PTHrP and its receptor (PPR) in the hair follicle is, as suspected, variable during the hair cycle, depending on the metabolic status. The PTHrP mRNA level decreases in early anagen and then peaks during late anagen, where transcripts of PTHrP are found in the outer root sheath of the non-permanent portion of the hair follicle [41]. It must be noted that the non-permanent portion of the hair follicle undergoes apoptosis during catagen [42]. On the other hand, PPR mRNA ex- 
pression, which is highest during angiogenesis, is relatively low in adulthood, only increasing during early anagen in the connective tissue sheath that surrounds the growing hair follicle [41]. The PTH/PTHrP signalling pathway is then, as it has already been said, the next part of the complex epithelial-mesenchymal cross-acting regulation of hair cycling [42].

Numerous studies confirmed the suspected role of $\mathrm{PTH} / \mathrm{PTHrP}$ as a proliferation-regulating factor. First, human PTHrP(1-34) peptide and human PTH(1-34) have been shown to inhibit proliferation and induce terminal differentiation of cultured human keratinocytes [43]. Next, applying the PTH antagonist, a bovine PTH (7-34) amide to these cells resulted in reduced proliferation and inhibited cornified envelope formation. Incorporation of thymidine, as a marker of the studied cells' proliferation, exhibited alterations, which further confirmed the potent antiproliferative role of PTHrP [34].

Through investigations into the mechanisms of antiproliferative activity of $\mathrm{PTH} / \mathrm{PTHrP}$, it has been found that the $\mathrm{N}$-terminal portion of PTHrP (a fragment similar to PTH) has also been reported to inhibit angiogenesis in endothelial cells in vitro when there is an overexpression of PTHrP reduced tumour vascularization in vivo [42]. The next evidence for this specific way of action of PTHrP is that premature angiogenesis is also found as a problem leading to the chondrodystrophy associated with PTHrP and PPR knockout mice [44]. Transgenic mice overexpressing PTHrP (K14-PTHrP mice) with a measured 10fold increase in PTHrP content in the skin, but with no hypercalcaemia/PTHrP in the circulation, presented disturbances in hair follicle growth and function. In these mice, the ventral skin almost completely lacked hair follicles, and the dorsal coat was shorter and thinner in adulthood [37]. This was apparently the result of a primary failure of follicle induction in the studied transgenic K14-PTHrP mice, and it confirmed an antiproliferative impact of PTH agonists. An interesting phenomenon was that the phenotype presented by male transgenic mice was less severe than that in females, which could, in the authors' opinion, suggest the protective role of androgens [45] but requires further studies [37]. Other immunohistological studies demonstrated the presence of PTHrP, most notably in developing tissues and also in developing skin appendages [46].

Summarizing, PTHrP overexpression leads to a shortened hair circle by reducing proliferation in the matrix during late anagen. As PTHrP has been proven to be a regulator of angiogenesis, the vasculature of the hair follicle in K14-PTHrP mice was, as suspected, also altered

Impact of PTH on Hair Follicle Physiology:

Implications for CIA Treatment
[42]. It is understandable that anagen hair units need extensive angiogenesis for their highly proliferating cells [47]. In accordance with the suspected influence of decreased angiogenesis on the hair follicle diameter, a 33\% decrease in vessel length and vessel diameter was observed during the study with transgenic mice that overexpressed PTHrP. On the other hand, in PTHrP knockout mice (lack of PTHrP/PPR expression) increased vasculature was observed [42]. There is still a question about the pathomechanism of the regulation of angiogenesis caused by PTHrP/PPR signalling. It was previously discovered that vascular endothelial growth factor expression is correlated with the regulation of the hair growth cycle [48]. However, in the study of Diamond et al. [42], no changes in the expression of vascular endothelial growth factor or fibroblast growth factor 2 accompanied a reduced vasculature in the $\mathrm{KrP}$ mice, so a direct influence of PPR signalling on angiogenesis is speculated.

The role of PTH/PTHrP signalling in skin and hair follicle physiology cannot be denied. Agonists and antagonists of PTH that connect to PPR alter the proliferation rate and the expression of differentiation markers in vitro/in vivo [34]. From this point of view, PTH antagonists have been suspected to be a possible target for scientists trying to discover a topical drug promoting hair growth in vivo [49].

\section{Dermatological Manifestations of Parathyroid-Related Disorders}

Despite the potent role of $\mathrm{PTH}$ as a regulating factor in the hair growth cycle, the dermatological manifestations of parathyroid-related disorders, and especially hair growth disorders, are rarely a subject of dermatologists' and endocrinologists' interest [5].

Sporadic cases of PTH-related hair symptoms were reported in familial syndromes of hyper-/hypoparathyroidism [50-52].

PTH, together with calcitriol, regulates calcium and phosphate homeostasis [53]. Therefore, the majority of symptoms of hypo- or hyperparathyroidism could be caused by hypo- or hypercalcaemia. Parathyroid glands respond to alterations of calcium concentration in serum through their calcium-sensing receptors. These receptors are expressed in the parathyroid glands and also in highly proliferating tissues [54]. Parathyroid disorders are generally divided into hypo- and hyperparathyroidism.

Sporadic primary hyperparathyroidism is still the most frequently occurring among parathyroid-related 
diseases [55]. The inherited cases include isolated hyperparathyroidism (with hyperparathyroidism-jaw tumour syndrome), familial benign hypercalcaemic hypocalciuria and the group of multiple endocrine neoplasia (MEN) syndromes [53]. Hypoparathyroidism is associated with sporadic hypoparathyroidism, hypoparathyroidism associated with polyglandular failure, pseudohypoparathyroidism and autosomal dominant hypocalcaemia.

\section{Hyperparathyroidism and Its Dermatological Manifestations}

Hyperparathyroidism is diagnosed in the case of an inappropriate secretion of $\mathrm{PTH}$ with a coexisting increase in calcium serum concentration. In sporadic cases, primary hyperparathyroidism affects mostly women, in their mid-50s, who are usually asymptomatic. The first sign of this condition is usually an incidentally detected hypercalcaemia. Sporadic hyperparathyroidism is associated with a single adenoma in approximately $80 \%$ of cases or with multiple adenomas in $2-4 \%$ of cases. It could also be caused by hyperplasia of the parathyroid glands in $10-15 \%$ of cases, or be related to parathyroid carcinoma in 1-2\% of cases [55]. Despite the molecular role of PTH, which can regulate the proliferative activity of skin appendages, such as hair follicles, there is still a lack of evidence that skin and hair abnormalities are directly related to primary hyperparathyroidism. An exception may be metastatic calcifications associated with hypercalcaemia [53]. And also, a relation with chronic urticaria has been described in a few case reports [56].

Hereditary disorders of hyperparathyroidism are familial isolated hyperparathyroidism, hyperparathyroidism-jaw tumour syndrome and multiple neoplasia syndromes. In familial isolated hyperparathyroidism and in hyperparathyroidism-jaw tumour syndrome, skin and hair abnormalities were not observed $[57,58]$. MEN type 1 (MEN1) includes: hyperparathyroidism in almost $90 \%$ of cases, pancreatic tumours in $40 \%$ of the cases, and pituitary tumours in $20 \%$ of cases (especially as prolactinoma, foregut carcinoid or adrenal tumours). It is also commonly connected with skin neoplasms. In MEN1, patients with facial angiofibromas could be noticed in $85 \%$ of cases, collagenomas in $70 \%$ of cases and lipomas in $30 \%$ of cases [59]. Angiofibromas and collagenomas are almost always specific for MEN1 diagnosis. Starting in the second decade of life, angiofibromas in MEN1 are located on the lips and centrally on the face, presenting as multiple, a few millimetres in a diameter, skin-coloured, ery- thematous papules. Collagenomas are located usually on the trunk and neck, presenting as skin-coloured papules and nodules, either as solitary or more numerous lesions. Other skin findings include single or multiple lipomas, cafe-au-lait lesions or hyperpigmentations. In case of other hormonal disturbances acanthosis nigricans, acrochordons and other hormone-related skin lesions could be present. Hair loss in patients with MEN1 is highly expected, especially in the case of prolactinoma; however, researchers' descriptions of this syndrome almost constantly miss the hair growth problem [53]. The MEN2a syndrome (Sipple's syndrome) includes medullary thyroid cancer (which is present in $100 \%$ of the cases), phaeochromocytoma (seen in $40 \%$ of patients) and primary parathyroid hyperplasia (noticed in about $10-20 \%$ of cases). MEN2a is associated with mutations in the RET protooncogene. This syndrome in inherited in an autosomal dominant manner. The symptoms of MEN2a include medullary thyroid cancer, pheochromocytoma and (in $10-20 \%$ of patients) primary parathyroid hyperplasia. The latter seems to be associated with cutaneous macular and lichen amyloidosis. Skin lesions in these cases are located predominantly in the interscapular area as pruritic, scaly, lichenoid and hyperpigmented papules with histopathology of lichen amyloidosus $[53,60]$. In MEN2b syndrome, medullary thyroid cancer is also the most dominant feature, being associated with phaeochromocytoma, but without (or very rarely with) hyperparathyroidism. The genetic diagnosis of MEN2a and MEN2b is obligatory to identify the asymptomatic family members with the mutation in the RET proto-oncogene. If the mutation is present, a prophylactic strumectomy is provided as the medullary thyroid cancer is still life-threatening [61].

Secondary hyperparathyroidism (in the case of renal failure) is connected with multiple symptoms of the underlying end-stage renal disease. Hyperparathyroidism is the result of hyperphosphataemia and hypocalcaemia that stimulate the parathyroid glands' growth and secretion leading to hyperplasia or multiple adenomatosis of the parathyroid glands. Pruritus and metastatic calcifications are the most frequent dermatological symptoms in this case $[62,63]$. Generally, in the condition of altered calcium and phosphate serum concentrations, calcinosis cutis could be present in all parathyroid disorders, with the highest prevalence in the case of renal failure. It is seen as benign, firm, white nodules/papules that could resolve after stabilization of calcium-phosphate homeostasis, or it could lead to calciphylaxis and necrosis of the skin [64]. Foci of skin calciphylaxis are usually noticed in the case of end-stage renal failure and in the case of secondary or 
tertiary hyperparathyroidism; however, it is seldom presented in the case of primary hyperparathyroidism [65].

Hyperparathyroidism tends to be cured radically by parathyroidectomy, which should be recommended to all symptomatic patients. However, through observation, evaluation and stabilization of hormonal homeostasis, in conjunction with the evaluation of the clinical and genetic diagnosis, it can be decided what kind of management should be provided in each individual case [66]. Skin manifestations, such as angiofibromas, collagenomas and lipomas, noticed mainly in MEN syndromes, can be surgically excised for cosmetic indications. Angiofibromas may be treated with pulsed dye, KTP (potassium titanyl phosphate; $\mathrm{KTiOPO}_{4}$ ) or $\mathrm{CO}_{2}$ lasers [53]. The most complex patients are those with secondary hyperparathyroidism related to renal failure with multiple symptoms and severe dysregulation of systemic homeostasis. The most important here is still systemic treatment aimed at obtaining hormonal and mineral homeostasis [53].

As hair growth disorders often go unreported in a large group of patients with hyperparathyroidism, the question about the real presence or absence of hair growth disturbances in case of elevated PTH arises.

\section{Hypoparathyroidism and Its Cutaneous Manifestations}

Hypoparathyroidism is diagnosed in case of hypocalcaemia, usually, with an inappropriate response of the parathyroid glands or, in case of elevated PTH levels, a lack of responsiveness to its effects, known as pseudohypoparathyroidism [52]. The most frequent, nowadays, is still the hypoparathyroidism secondary to thyroidectomy (with parathyroidectomy or in the case of fibrotic changes after surgery and decreased vascularization of the parathyroid glands). However, there are also cases of isolated idiopathic, congenital sporadic or inherited hypoparathyroidism (di George syndrome, Albright's osteodystrophy) or cases of hypoparathyroidism related to auto-immune disorders like auto-immune polyglandular syndrome type 1 . In all cases of hypoparathyroidism, the symptoms are correlated with low serum-ionized calcium levels including paresthesia, muscle cramps, tetany, laryngo- and bronchospasm, extrapyramidal signs, seizures and dental abnormalities. Classically reported skin symptoms refer to dry, rough, keratotic and puffy skin [52]. The nails are noted to be ridged, with onycholysis. Hair is reported as coarse and brittle. Also, persistent or recurrent candidal infections of the skin or/and especial- ly mucous membranes are thought to be associated with different types of hypoparathyroidism; however, typically they are noticed in multiple auto-immune endocrinopathies [53]. The induction of general psoriasis, pustular psoriasis or impetigo herpetiformis that are noticed in cases of hypoparathyroidism becomes understandable as PTH has been proven to regulate the proliferation of skin and hair follicles $[67,68]$. Unfortunately, although subcutaneous PTH injections have been proven to be safe and effective in the treatment of parathyroid-related symptoms, such therapy has not received Food and Drug Administration approval for the indication of hypoparathyroidism.

As in hyperparathyroidism, the suspected hair growth abnormalities are rarely reported. There are single studies that show a significant prevalence of hair loss in patients with hypoparathyroidism. In a study of 25 patients with a symptomatic permanent hypoparathyroidism (following surgery), skin and hair symptoms were estimated to be present in $68 \%$ of patients, causing a greater impact on the quality of life than other symptoms related to hypocalcaemia, such as paresthesia, joint pain and osteoporosis [69].

The results of another study also correspond to the direct role of PTH in the skin and its appendages. In a studied group of 21 patients with hypoparathyroidism secondary to surgery, mucocutaneous symptoms were noticed in more than $76 \%$ of patients, and symptoms related to hair growth abnormalities were the most frequent among them. In fact, axillary hair loss was found in $61.9 \%$ of patients, loss of pubic hair in $52.38 \%$ of patients, and coarsening of body hair was detected in $47.62 \%$ of patients. Additionally, alopecia areata was present in $9.52 \%$ of the studied patients. Other mucocutaneus findings included brittle, ridged nails leading to onycholysis, dry, xerotic skin, pustular psoriasis, acneiform eruption and bullous impetigo. Surprisingly, the symptom most commonly associated with hypoparathyroidism, oral candidiasis, was found only in 1 patient [70].

\section{Trichoscopy in Patients with Parathyroid Gland Disorders}

Trichoscopy is dermoscopy of the hair and scalp. Analysis of different structures, which is performed during a trichoscopy examination, includes the evaluation of hair shafts, hair follicle openings (dots), perifollicular epidermis and blood vessels. This method allows for a differential diagnosis of various causes of hair loss [71]. As 
PTH may facilitate the anagen-to-catagen/telogen transition and induce telogen effluvium, trichoscopy in these patients will show features typical of telogen effluvium of other origin, such as a decrease in hair shafts per follicular unit, perifollicular discoloration and upright regrowing hairs [71]. It must be highlighted that the majority of patients with hyperparathyroidism are middle-aged and postmenopausal women, so differentiating it from androgenetic alopecia and senescent alopecia is crucial. Research studies are ongoing to identify whether there are more characteristic features of hair conditions in the course of hyperparathyroidism, which can be identified or diagnosed by trichoscopy.

\section{PPR Ligands as a Potential Treatment Option for Hair Disorders}

The hair follicles are an interesting target for topical drugs [72-74]. The putative role of PTH/PTHrP and PPR signalling suggests that PPR ligands could be candidates for topical drugs that can stimulate or inhibit hair growth. However, PTH and PTHrP are very unstable peptides, so it is difficult to create topically deliverable PTH/PTHrP drugs. As the antagonists of PPR show a stimulating effect on the proliferation of hair follicle cells, they are an interesting potential target for researchers [75-77]. Safer et al. [49] attempted to apply PTH(7-34) - antagonist of PPR topically to the skin of SKH-1 hairless mice. SKH-1 mice lose all external hair in their first hair cycle after birth. Promisingly, after 1 week of treatment, a stimulation of hair growth was observed. When compared to the study control group, the hairs were $216 \%$ longer and a $40 \%$ increase in the number of hairs was reported. On average, $43 \%$ more hair follicles stained positive with $\mathrm{H}$-thymidine incorporation and 5-bromo-2-deoxyuridine into DNA as markers of active proliferation. There was no difference in serum calcium concentration between the PTH(7-34)-treated mice and the controls, indicating that there were no systemic adverse effects of this topical therapy. The increase in hair growth after treatment with PTH antagonist, applied topically as a liposome cream, was very promising for further research [49]. It may be hypothesized that PTH antagonists are a potential treatment option in hair loss disorders.

Also, the proliferation-inhibiting effect of PTH/ PTHrP agonists may be beneficial in clinical practice. $\mathrm{PTH} / \mathrm{PTHrP}$ agonists were used as effective experimental treatment for psoriasis. A cream created with PTH(1-34) - an agonist of PPR - inhibited the patho- logical hyperproliferation of the skin [75]. It may be hypothesized that PTH antagonists may be a potential treatment option in hair loss disorders [75].

\section{PPR Agonists and Antagonists as a Potential Treatment Option for Chemotherapy-Induced Alopecia}

PTH agonists and antagonists have been shown to improve hair growth after chemotherapy. Chemotherapy of cancer patients evokes many side effects, and chemotherapy-induced alopecia (CIA) is, in fact, one of the constant adverse side effects of a cancer therapy $[78,79]$. CIA results in a depressed mood, causes stress and a high level of discomfort for treated patients $[80,81]$. The incidence and severity of CIA vary depending on personal susceptibility and the chemotherapy protocol, but the general prevalence of CIA is estimated to be in the range of 65$85 \%$ in patients receiving chemotherapy [82]. Hair loss in this condition is associated with an impaired regrowth of hairs, which are thinner and more fragile. The mechanisms considered to be connected with this process are also multiple and depend on the type of chemotherapeutic agent. However, CIA is usually linked to apoptosisrelated damage of the hair follicle [83]. Many cytostatics act also by decreasing proliferation of the hair follicle, where, as it is already known, the PTH-PPR signalling is a potent way to alter the proliferative activity [45]. Treatment of CIA is highly needed, but there are still no recommended models of treatment. The only one, and which is still controversial, could be scalp hypothermia during chemotherapy courses [84].

PTH agonists and antagonists which are proven to alter hair growth have been tried in this problematic hair loss disorder. It was shown that both PTH agonists and antagonists effectively altered the hair follicle response to CIA in a depilated mouse model. However, the regrowth of hair was dependent on a frequent intraperitoneal injection of peptides, suggesting a dose-dependent effect and a problematic bioprofile of the administered drug [45]. In another study, Katikaneni et al. [85-87] combined PTH with a collagen binding domain (PTH-CBD) to promote the distribution and retention of $\mathrm{PTH}(1-33)$ agonist in well-vascularized, high-collagen-containing tissues, such as the skin. The results of that study are promising. A single dose of the peptide $\mathrm{PTH}(1-33)$ caused a hair regrowth in mice within 30 days and an increase in the number of anagen phase VI hair follicles. Surprisingly, PTH-CBD antagonists have no significant effect on hair 
growth [88]. In another study, PTH agonists and antagonists were CBD-linked and applied subcutaneously to mice treated with cyclophosphamide. Hair damage caused by chemotherapy was prevented and a re-establishment of hair growth was obtained. In that study, PTHCBD peptide also caused a repigmentation in patients with alopecia provoked by cyclophosphamide.

As there is still no approved or effective treatment for patients with CIA, PTH agonists or antagonists seem to be peptides with a promising potential in preventing CIA in early treatment $[85,86]$. The $\mathrm{PTH}(7-34)-\mathrm{CBD}$ and PTH-CBD subcutaneous injection in mice initially resulted in whole-animal distribution and, later, was followed by the redistribution of applied peptides to collagen-rich tissues such as bone and skin. No symptoms of hyperparathyroidism or calcium serum level alterations were found in the study [88]. The majority of hairs in the histopathological samples of treated mice stayed long in anagen VI, confirming the very potent role of the peptides used. It is noteworthy to mention that PTH-CBD could also be applied in the prophylaxis of reduced bone mineral density associated with chemotherapy. Such results were obtained in the in vivo study, where mice were treated with PTH-CBD subcutaneously before chemotherapy was started [88]. As parallel studies confirm, the antiproliferative impact of PTH agonists and the proliferative role of PTH antagonists in the results of the studies of Katikaneni et al. [85-88] (where both agonist and antagonist caused hair growth improvement in CIA) could be surprising. However, it must be remembered that $\mathrm{PTH}(1-$ 34) peptide could have both an agonistic and antagonistic impact, and aminoterminal truncation has been shown to convert PTH from its agonist to antagonist form [89].

Study results had been so promising that clinical trials with topically administered PTH(7-34) applied in CIA were started in IGI Laboratories. However, despite great hope, the results of phase II clinical trials appeared to be disappointing, and the trial was stopped by the parent company IGI Laboratories [49]. The lack of the expected effect could have been related to rapid utilization, clearance and problematic distribution of PTH antagonistic analogues used in the treatment. It has to be underlined that the biological activity of the antagonist portion is much weaker than that of the PTH agonist portion. Additionally, the antagonist portion [PTH(7-34) amide] is more fragile and unstable. From this point of view, treatment efficacy with a PTH antagonist could be difficult to predict and may be dose dependent. However, clinical trials are now being performed with a purer antagonist peptide which is referred to as $\mathrm{PTH}(7-33)$ [49]. Summarizing

Impact of PTH on Hair Follicle Physiology:

Implications for CIA Treatment the current knowledge, PTHrP and PTH generally accelerate the hair cycle (initiate the anagen phase and evoke the transition from anagen to catagen). The reason for the differences in the way that agonists and antagonists of PPR act in the hair growth cycle has recently been discovered. Application of PTHrP agonists is beneficial in the case of inhibition of Wnt signalling (hairless mouse study, potentially androgenetic alopecia), as the agonists prolong the anagen phase by inhibiting anagen-to-catagen transitions. On the other hand, in the case of CIA and in the engrafted $\mathrm{C} 3 \mathrm{H} / \mathrm{HeJ}$ mouse model for alopecia areata, agonists could have more potential. They accelerate hair regrowth by stimulating replacement of damaged hair follicles. PTHrP antagonists may only provide short-term improvement by prolonging the anagen phase of existing follicles, but they end up inhibiting the hair cycle and reducing hair growth [16].

\section{Conclusion}

Hair disorders and hair loss are not life-threatening; however, they adversely affect self-confidence, self-esteem and quality of life. Until recently, clinically obvious hair growth disorders associated with parathyroid-related disorders had not been reported in the literature. In contrast to this lack of data, PPR agonists and antagonists have been shown to impact the hair growth cycle in numerous studies in vitro and in vivo. PTH/PTHrP antagonists were shown to stimulate proliferation of hair follicle cells and hair growth. Topical application of PPR ligands induced positive changes in hair growth, especially in CIA. These data may indicate that PPR ligands may be safe and potentially effective topical drugs in the prevention or treatment of CIA. Despite the molecular evidence for the significant role of PTH/PTHrP and their receptors in hair biology, the possible clinical use of these potent cell regulators remains to be determined.

\begin{tabular}{|c|c|}
\hline References & $\begin{array}{l}\text { BreitkopfT, Leung G, Yu M, Wang E, McElwee } \\
\text { KJ: The basic science of hair biology: what are } \\
\text { the causal mechanisms for the disordered hair } \\
\text { follicle? Dermatol Clin 2013;31:1-19. } \\
2 \text { Sehgal VN, Srivastava G, Aggarwal AK, Mid- } \\
\text { ha R: Hair biology and its comprehensive se- } \\
\text { quence in female pattern baldness: diagnosis } \\
\text { and treatment modalities. Part I. Skinmed } \\
\text { 2013;11:39-45; quiz 45. } \\
3 \text { Nguyen JV: The biology, structure, and func- } \\
\text { tion of eyebrow hair. J Drugs Dermatol 2014; } \\
\text { 13:s12-s16. }\end{array}$ \\
\hline
\end{tabular}


$\checkmark 4$ Chen WC, Zouboulis CC: Hormones and the 23 Schneider MR, Schmidt-Ullrich R, Paus R: pilosebaceous unit. Dermatoendocrinol 2009; $1: 81-86$.

5 Olszewska M, Warszawik O, Rakowska A, Slowinska M, Rudnicka L: Methods of hair loss evaluation in patients with endocrine disorders. Endokrynol Pol 2010;61:406-411.

6 Ben-Shlomo I, Younis JS: Basic research in 25 PCOS: are we reaching new frontiers? Reprod Biomed Online 2014;28:669-683.

7 Herskovitz I, Tosti A: Female pattern hair $>26$ loss. Int J Endocrinol Metab 2013;11:e9860.

-8 Billoni N, Buan B, Gautier B, Gaillard O, Mahe YF, Bernard BA: Thyroid hormone receptor betal is expressed in the human hair follicle. Br J Dermatol 2000;142:645-652.

$\checkmark 9$ Lutz G: Hair loss and hyperprolactinemia in women. Dermatoendocrinology 2012;4:65-71.

10 Narad S, Pande S, Gupta M, Chari S: Hormonal profile in Indian men with premature androgenetic alopecia. Int J Trichol 2013;5: 69-72.

11 Reid IR: Vitamin D: present and future. Rev Clin Esp 2014;214:383-384.

12 Varsavsky M, Alonso G, Garcia-Martin A: Vi- 30 tamin D: present and future. Rev Clin Esp 2014;214:396-402.

13 Malloy PJ, Feldman D: The role of vitamin D receptor mutations in the development of alopecia. Mol Cell Endocrinol 2011;347:90-96.

$\checkmark 14$ Rasheed H, Mahgoub D, Hegazy R, El-Komy M, Abdel Hay R, Hamid MA, Hamdy E: Serum ferritin and vitamin $\mathrm{D}$ in female hair loss: do they play a role? Skin Pharmacol Physiol 2013;26:101-107.

15 Thomson M, McCarroll J, Bond J, GordonThomson C, Williams DE, Moore GP: Parathyroid hormone-related peptide modulates signal pathways in skin and hair follicle cells. Exp Dermatol 2003;12:389-395.

$\$ 16$ Gensure RC: Parathyroid hormone-related peptide and the hair cycle - is it the agonists or the antagonists that cause hair growth? Exp Dermatol 2014;23:865-867.

17 Kanti V, Bonzel A, Stroux A, Proquitte H, Buhrer C, Blume-Peytavi U, Bartels NG: Postnatal maturation of skin barrier function in premature infants. Skin Pharmacol Physiol 2014;27:234-241.

18 Hardy MH: The secret life of the hair follicle. Trends Genet 1992;8:55-61.

19 Cotsarelis G, Sun TT, Lavker RM: Label-retaining cells reside in the bulge area of pilosebaceous unit: implications for follicular stem cells, hair cycle, and skin carcinogenesis. Cell 1990;61:1329-1337.

20 Chuong CM, Hou L, Chen PJ, Wu P, Patel N, Chen Y: Dinosaur's feather and chicken's tooth? Tissue engineering of the integument. Eur J Dermatol 2001;11:286-292.

21 Oliver RF: Whisker growth after removal of the dermal papilla and lengths of follicle in the hooded rat. J Embryol Exp Morphol 1966;15: 331-347.

22 Millar SE: Molecular mechanisms regulating hair follicle development. J Invest Dermatol 2002;118:216-225.
The hair follicle as a dynamic miniorgan. Curr Biol 2009;19:R132-R142.

24 Sehgal VN, Srivastava G, Aggarwal AK, Midha R: Hair biology and its comprehensive sequence in female pattern baldness: treatment modalities. Part III. Skinmed 2013;11:287-290.

5 Stenn K: Exogen is an active, separately controlled phase of the hair growth cycle. J Am Acad Dermatol 2005;52:374-375.

26 Hanakawa Y, Li H, Lin C, Stanley JR, Cotsarelis G: Desmogleins 1 and 3 in the companion layer anchor mouse anagen hair to the follicle. J Invest Dermatol 2004;123:817-822.

27 Rebora A, Guarrera M: Kenogen. A new phase of the hair cycle? Dermatology 2002; 205:108-110.

28 Paus R, Cotsarelis G: The biology of hair follicles. N Engl J Med 1999;341:491-497.

29 Sehgal VN, Srivastava G, Aggarwal AK, Midha R: Hair biology and its comprehensive sequence in female pattern baldness: clinical connotation diagnosis and differential diagnosis. Part II. Skinmed 2013;11:227-236.

30 Finner AM: Nutrition and hair: deficiencies and supplements. Dermatol Clin 2013;31: 167-172.

31 Bodo E, Kromminga A, Biro T, Borbiro I, Gaspar E, Zmijewski MA, van Beek N, Langbein L, Slominski AT, Paus R: Human female hair follicles are a direct, nonclassical target for thyroid-stimulating hormone. J Invest Dermatol 2009;129:1126-1139.

32 Finke R: Thyroid diseases as a cause of skin changes and hair loss (in German). Med Monatsschr Pharm 2001;24:147-153.

33 Chen GD, Li M, Tanaka C, Bielefeld EC, Hu BH, Kermany MH, Salvi R, Henderson D: Aging outer hair cells (OHCS) in the Fischer 344 rat cochlea: function and morphology. Hear Res 2009;248:39-47.

34 Holick MF, Ray S, Chen TC, Tian X, Persons KS: A parathyroid hormone antagonist stimulates epidermal proliferation and hair growth in mice. Proc Natl Acad Sci U S A 1994;91:8014-8016.

35 Burtis WJ, Wu T, Bunch C, Wysolmerski JJ, Insogna KL, Weir EC, Broadus AE, Stewart AF: Identification of a novel 17,000-dalton parathyroid hormone-like adenylate cyclasestimulating protein from a tumor associated with humoral hypercalcemia of malignancy. J Biol Chem 1987;262:7151-7156.

36 Merendino JJ Jr, Insogna KL, Milstone LM, Broadus AE, Stewart AF: A parathyroid hormone-like protein from cultured human keratinocytes. Science 1986;231:388-390.

37 Wysolmerski JJ, Broadus AE, Zhou J, Fuchs E, Milstone LM, Philbrick WM: Overexpression of parathyroid hormone-related protein in the skin of transgenic mice interferes with hair follicle development. Proc Natl Acad Sci U S A 1994;91:1133-1137.

38 Pun KK, Arnaud CD, Nissenson RA: Parathyroid hormone receptors in human dermal fibroblasts: structural and functional characterization. J Bone Miner Res 1988;3:453-460.
39 Orloff JJ, Ganz MB, Ribaudo AE, Burtis WJ, Reiss M, Milstone LM, Stewart AF: Analysis of PTHrP binding and signal transduction mechanisms in benign and malignant squamous cells. Am J Physiol 1992;262:E599E607.

40 Gardella TJ, Juppner H: Molecular properties of the PTH/PTHrP receptor. Trends Endocrinol Metab 2001;12:210-217.

41 Cho YM, Woodard GL, Dunbar M, Gocken T, Jimenez JA, Foley J: Hair-cycle-dependent expression of parathyroid hormone-related protein and its type I receptor: evidence for regulation at the anagen to catagen transition. J Invest Dermatol 2003;120:715-727.

42 Diamond AG, Gonterman RM, Anderson $\mathrm{AL}$, Menon K, Offutt CD, Weaver CH, Philbrick WM, Foley J: Parathyroid hormone-related protein and the $\mathrm{PTH}$ receptor regulate angiogenesis of the skin. J Invest Dermatol 2006;126:2127-2134.

43 Milstone LM: Effector functions of epidermal keratinocytes. Ann NY Acad Sci 1988;548:13.

44 Bakre MM, Zhu Y, Yin H, Burton DW, Terkeltaub R, Deftos LJ, Varner JA: Parathyroid hormone-related peptide is a naturally occurring, protein kinase A-dependent angiogenesis inhibitor. Nat Med 2002;8:995-1003.

45 Peters EM, Foitzik K, Paus R, Ray S, Holick MF: A new strategy for modulating chemotherapy-induced alopecia, using PTH/PTHrP receptor agonist and antagonist. J Invest Dermatol 2001;117:173-178.

46 Campos RV, Asa SL, Drucker DJ: Immunocytochemical localization of parathyroid hormone-like peptide in the rat fetus. Cancer Res 1991;51:6351-6357.

47 Mecklenburg L, Tobin DJ, Muller-Rover S, Handjiski B, Wendt G, Peters EM, Pohl S, Moll I, Paus R: Active hair growth (anagen) is associated with angiogenesis. J Invest Dermatol 2000;114:909-916.

48 Yano K, Brown LF, Detmar M: Control of hair growth and follicle size by VEGF-mediated angiogenesis. J Clin Invest 2001;107:409-417.

49 Safer JD, Ray S, Holick MF: A topical parathyroid hormone/parathyroid hormone-related peptide receptor antagonist stimulates hair growth in mice. Endocrinology 2007;148: $1167-1170$

50 Masmoudi A, Chermi ZM, Marrekchi S, Raida BS, Boudaya S, Mseddi M, Jalel MT, Turki $\mathrm{H}$ : Cowden syndrome. J Dermatol Case Rep 2011;5:8-13.

51 Van Beelen E, Leijendeckers JM, Admiraal RJ, Huygen PL, Hoefsloot LH, Pennings RJ, Snik AF, Kunst HP: Audiometric characteristics of a Dutch family with a new mutation in GATA3 causing HDR syndrome. Audiol Neurootol 2014;19:106-114.

52 Jabbour SA: Cutaneous manifestations of endocrine disorders: a guide for dermatologists. Am J Clin Dermatol 2003;4:315-331.

53 Fuleihan Gel H, Rubeiz N: Dermatologic manifestations of parathyroid-related disorders. Clin Dermatol 2006;24:281-288. 
54 Brown EM, Pollak M, Seidman CE, Seidman JG, Chou YH, Riccardi D, Hebert SC: Calcium-ion-sensing cell-surface receptors. N Engl J Med 1995;333:234-240.

-55 Bilezikian JP, Brandi ML, Rubin M, Silverberg SJ: Primary hyperparathyroidism: new concepts in clinical, densitometric and biochemical features. J Intern Med 2005;257:6-17.

56 Dagher HN, Aboujaoude ZC, Jabbour SA: Chronic urticaria: an unusual initial manifestation of primary hyperparathyroidism. Endocr Pract 2002;8:47-49.

57 Marx SJ: Molecular genetics of multiple endocrine neoplasia types 1 and 2. Nat Rev Cancer 2005;5:367-375.

58 Marx SJ, Stratakis CA: Multiple endocrine neoplasia - introduction. J Intern Med 2005 257:2-5

59 Pack S, Turner ML, Zhuang Z, Vortmeyer AO, Boni R, Skarulis M, Marx SJ, Darling TN: Cutaneous tumors in patients with multiple endocrine neoplasia type 1 show allelic deletion of the MEN1 gene. J Invest Dermatol 1998;110:438-440.

-60 Verga U, Fugazzola L, Cambiaghi S, Pritelli C, Alessi E, Cortelazzi D, Gangi E, Beck-Peccoz P: Frequent association between MEN2a and cutaneous lichen amyloidosis. Clin Endocrinol (Oxf) 2003;59:156-161.

61 Ceccherini I, Romei C, Barone V, Pacini F, Martino E, Loviselli A, Pinchera A, Romeo G: Identification of the Cys634->Tyr mutation of the RET proto-oncogene in a pedigree with multiple endocrine neoplasia type $2 \mathrm{a}$ and localized cutaneous lichen amyloidosis. J Endocrinol Invest 1994;17:201-204.

-62 Hafner J, Keusch G, Wahl C, Sauter B, Hurlimann A, von Weizsacker F, Krayenbuhl M, Biedermann K, Brunner U, Helfenstein U: Uremic small-artery disease with medial calcification and intimal hyperplasia (so-called calciphylaxis): a complication of chronic renal failure and benefit from parathyroidectomy. J Am Acad Dermatol 1995;33:954962.

-63 Angelis M, Wong LL, Myers SA, Wong LM: Calciphylaxis in patients on hemodialysis: a prevalence study. Surgery 1997;122:10831089; discussion 1089-1090.

64 Hafner J, Keusch G, Wahl C, Burg G: Calciphylaxis: a syndrome of skin necrosis and acral gangrene in chronic renal failure. Vasa 1998;27:137-143.

65 Mirza I, Chaubay D, Gunderia H, Shih W, ElFanek H: An unusual presentation of calciphylaxis due to primary hyperparathyroidism. Arch Pathol Lab Med 2001;125:13511353.

66 Bilezikian JP, Potts JT Jr, Fuleihan Gel H, Kleerekoper M, Neer R, Peacock M, Rastad J, Silverberg SJ, Udelsman R, Wells SA: Summary statement from a workshop on asymptomatic primary hyperparathyroidism: a perspective for the 21st century. J Clin Endocrinol Metab 2002;87:5353-5361.

67 Lee Y, Nam YH, Lee JH, Park JK, Seo YJ: Hypocalcaemia-induced pustular psoriasis-like skin eruption. Br J Dermatol 2005;152:591593.

68 Gueydan M, Folchetti G, Christofilis MA, Valero R, Grob JJ, Vialettes B: Impetigo herpetiformis, a rare manifestation of severe hypocalcemia (in French). Ann Endocrinol (Paris) 2002;63:502-504.

-69 Bohrer T, Pasteur I, Lyutkevych O, Fleischmann P, Tronko M: Permanent hypoparathyroidism due to thyroid cancer surgical procedures in patients exposed to radiation in the Chernobyl, Ukraine, nuclear reactor accident (in German). Dtsch Med Wochenschr 2005; 130:2501-2506.

70 Sarkar S, Mondal M, Das K, Shrimal A: Mucocutaneous manifestations of acquired hypoparathyroidism: an observational study. Indian J Endocrinol Metab 2012;16:819-820.

71 Rudnicka L, Olszewska M, Rakowska A, Kowalska-Oledzka E, Slowinska M: Trichoscopy: a new method for diagnosing hair loss. J Drugs Dermatol 2008;7:651-654.

72 Lademann J, Richter H, Meinke M, Sterry W, Patzelt A: Which skin model is the most appropriate for the investigation of topically applied substances into the hair follicles? Skin Pharmacol Physiol 2010;23:47-52.

73 Lademann J, Knorr F, Richter H, Blume-Peytavi U, Vogt A, Antoniou C, Sterry W, Patzelt A: Hair follicles - an efficient storage and penetration pathway for topically applied substances. Summary of recent results obtained at the Center of Experimental and Applied Cutaneous Physiology, Charité Universitätsmedizin Berlin, Germany. Skin Pharmacol Physiol 2008;21:150-155.

74 Lademann J, Richter H, Schaefer UF, BlumePeytavi U, Teichmann A, Otberg N, Sterry W: Hair follicles - a long-term reservoir for drug delivery. Skin Pharmacol Physiol 2006;19: 232-236.

75 Holick MF, Chimeh FN, Ray S: Topical PTH(1-34) is a novel, safe and effective treatment for psoriasis: a randomized self-controlled trial and an open trial. Br J Dermatol 2003;149:370-376.

76 Schilli MB, Ray S, Paus R, Obi-Tabot E, Holick MF: Control of hair growth with parathyroid hormone (7-34). J Invest Dermatol 1997; 108:928-932.

77 Holick MF, Chen ML, Kong XF, Sanan DK: Clinical uses for calciotropic hormones 1,25-dihydroxyvitamin $\mathrm{D}_{3}$ and parathyroid hormone-related peptide in dermatology: a new perspective. J Investig Dermatol Symp Proc 1996;1:1-9.

78 Cline BW: Prevention of chemotherapy-induced alopecia: a review of the literature. Cancer Nurs 1984;7:221-228.

79 Lademann J, Rowert-Huber HJ, Haas N, Kluschke F, Patzelt A, Zastrow L, Lange-Asschenfeldt B, Jung S, Sterry W, Sehouli J: Palmoplantar erythrodysesthesia-like skin symptoms in patients under various chemotherapeutics: preventive and therapeutic options. Skin Pharmacol Physiol 2014;27:229233.
80 Lotfi-Jam K, Carey M, Jefford M, Schofield P, Charleson C, Aranda S: Nonpharmacologic strategies for managing common chemotherapy adverse effects: a systematic review. J Clin Oncol 2008;26:5618-5629.

-81 McGarvey EL, Baum LD, Pinkerton RC, Rogers LM: Psychological sequelae and alopecia among women with cancer. Cancer Pract 2001;9:283-289.

82 Trueb RM: Chemotherapy-induced hair loss. Skin Ther Lett 2010;15:5-7.

83 Schilli MB, Paus R, Menrad A: Reduction of intrafollicular apoptosis in chemotherapy-induced alopecia by topical calcitriol analogs. J Invest Dermatol 1998;111:598-604.

84 Christodoulou C, Tsakalos G, Galani E, Skarlos DV: Scalp metastases and scalp cooling for chemotherapy-induced alopecia prevention. Ann Oncol 2006;17:350.

85 Katikaneni R, Ponnapakkam T, Seymour A, Sakon J, Gensure R: Parathyroid hormone linked to a collagen binding domain promotes hair growth in a mouse model of chemotherapy-induced alopecia in a dose-dependent manner. Anticancer Drugs 2014;25: $819-825$

86 Katikaneni R, Ponnapakkam T, Matsushita $\mathrm{O}$, Sakon J, Gensure R: Treatment and prevention of chemotherapy-induced alopecia with PTH-CBD, a collagen-targeted parathyroid hormone analog, in a non-depilated mouse model. Anticancer Drugs 2014;25:3038.

87 Katikaneni R, Gulati R, Suh D, Sakon J, Seymour A, Ponnapakkam T, Gensure R: Therapy for alopecia areata in mice using parathyroid hormone agonists and antagonists, linked to a collagen-binding domain. J Investig Dermatol Symp Proc 2013;16:S61-S62.

$\$ 88$ Katikaneni R, Ponnapakkam T, Suda H, Miyata S, Sakon J, Matsushita O, Gensure RC: Treatment for chemotherapy-induced alopecia in mice using parathyroid hormone agonists and antagonists linked to a collagen binding domain. Int J Cancer 2012;131:E813E821.

89 Carter PH, Petroni BD, Gensure RC, Schipani E, Potts JT Jr, Gardella TJ: Selective and nonselective inverse agonists for constitutively active type-1 parathyroid hormone receptors: evidence for altered receptor conformations. Endocrinology 2001;142:1534-1545.

90 Enshell-Seijffers D, Lindon C, Kashiwagi M Morgan BA: Beta-catenin activity in the dermal papilla regulates morphogenesis and regeneration of hair. Dev Cell 2010;18:633-642.

-91 Ozeki M, Tabata Y: In vivo promoted growth of mice hair follicles by the controlled release of growth factors. Biomaterials 2003;24: 2387-2394

92 Hwang KA, Hwang YL, Lee MH, Kim NR, Roh SS, Lee Y, Kim CD, Lee JH, Choi KC: Adenosine stimulates growth of dermal papilla and lengthens the anagen phase by increasing the cysteine level via fibroblast growth factors 2 and 7 in an organ culture of mouse vibrissae hair follicles. Int J Mol Med 2012;29:195-201. 
$\$ 93$ Lee YR, Yamazaki M, Mitsui S, Tsuboi R, Ogawa $\mathrm{H}$ : Hepatocyte growth factor (HGF) activator expressed in hair follicles is involved in in vitro HGF-dependent hair follicle elongation. J Dermatol Sci 2001;25: 156-163.

94 Rishikaysh P, Dev K, Diaz D, Qureshi WM, Filip S, Mokry J: Signaling involved in hair follicle morphogenesis and development. Int J Mol Sci 2014;15:1647-1670.

95 Zhand Y, Yu J, Shi C, Huang Y, Wang Y, Yang T, Yang J: Lef1 contributes to the differentiation of bulge stem cells by nuclear translocation and cross-talk with the notch signaling pathway. Int J Med Sci 2013;10: 738-746.

$\$ 96$ McElwee KJ, Huth A, Kissling S, Hoffmann $\mathrm{R}$ : Macrophage-stimulating protein promotes hair growth ex vivo and induces anagen from telogen stage hair follicles in vivo. J Invest Dermatol 2004;123:34-40.

-97 Ahn SY, Pi LQ, Hwang ST, Lee WS: Effect of IGF-I on hair growth is related to the antiapoptotic effect of IGF-I and up-regulation of PDGF-A and PDGF-B. Ann Dermatol 2012;24:26-31.

$\$ 98$ Luetteke NC, Qiu TH, Pfeiffer RL, Oliver P, Smithies O, Lee DC: TGF alpha deficiency results in hair follicle and eye abnormalities in targeted and waved-1 mice. Cell 1993;73: 263-278.

99 Botchkarev VA, Botchkareva NV, Nakamura M, Huber O, Funa K, Lauster R, Paus R, Gilchrest BA: Noggin is required for induction of the hair follicle growth phase in postnatal skin. FASEB J 2001;15:2205-2214.

-100 Ouji Y, Yoshikawa M, Moriya K, Ishizaka S: Effects of Wnt-10b on hair shaft growth in hair follicle cultures. Biochem Biophys Res Commun 2007;359:516-522.

-101 Peters EM, Hansen MG, Overall RW, Nakamura M, Pertile P, Klapp BF, Arck PC, Paus $\mathrm{R}$ : Control of human hair growth by neurotrophins: brain-derived neurotrophic factor inhibits hair shaft elongation, induces catagen, and stimulates follicular transforming growth factor beta 2 expression. J Invest Dermatol 2005; 124:675-685.

102 Wilson N, Hynd PI, Powell BC: The role of BMP-2 and BMP-4 in follicle initiation and the murine hair cycle. Exp Dermatol 1999;8: 367-368.

103 Green MR, Couchman JR: Distribution of epidermal growth factor receptors in rat tissues during embryonic skin development, hair formation, and the adult hair growth cycle. J Invest Dermatol 1984;83:118-123.

104 Jacques BE, Dabdoub A, Kelley MW: FGF signaling regulates development and transdifferentiation of hair cells and supporting cells in the basilar papilla. Hear Res 2012; 289:27-39.

105 Higgins CA, Petukhova L, Harel S, Ho YY, Drill E, Shapiro L, Wajid M, Christiano AM: FGF5 is a crucial regulator of hair length in humans. Proc Natl Acad Sci U S A 2014;111: 10648-10653.
66 Harmon CS, Nevins TD: IL-1 alpha inhibits human hair follicle growth and hair fiber production in whole-organ cultures. Lymphokine Cytokine Res 1993;12;197-203.

107 Kwack MH, Ahn JS, Kim MK, Kim JC, Sung YK: Dihydrotestosterone-inducible IL-6 inhibits elongation of human hair shafts by suppressing matrix cell proliferation and promotes regression of hair follicles in mice. J Invest Dermatol 2012;132: 43-49.

108 Ryu S, Lee Y, Hyun MY, Choi SY, Jeong KH, Park YM, Kang H, Park KY, Armstrong CA, Johnson A, Song PI, Kim BJ: Mycophenolate antagonizes IFN-gamma-induced catagenlike changes via beta-catenin activation in human dermal papilla cells and hair follicles. Int J Mol Sci 2014;15:16800-16815.

109 Botchkarev VA, Welker P, Albers KM, Botchkareva NV, Metz M, Lewin GR, Bulfone-Paus S, Peters EM, Lindner G, Paus R: A new role for neurotrophin-3: involvement in the regulation of hair follicle regression (catagen). Am J Pathol 1998;153:785799.

110 Yu M, Kissling S, Freyschmidt-Paul P, Hoffmann R, Shapiro J, McElwee KJ: Interleukin- 6 cytokine family member oncostatin $M$ is a hair-follicle-expressed factor with hair growth inhibitory properties. Exp Dermatol 2008;17:12-19.

111 Foitzik K, Lindner G, Mueller-Roever S, Maurer M, Botchkareva N, Botchkarev V, Handjiski B, Metz M, Hibino T, Soma T, Dotto GP, Paus R: Control of murine hair follicle regression (catagen) by TGF-beta 1 in vivo. FASEB J 2000;14:752-760.

112 Hibino T, Nishiyama T: Role of TGF-beta2 in the human hair cycle. J Dermatol Sci 2004; 35:9-18.

113 Fischer TW, Slominski A, Zmijewski MA, Reiter RJ, Paus R: Melatonin as a major skin protectant: from free radical scavenging to DNA damage repair. Exp Dermatol 2008; 17: 713-730.

114 Peters EM, Liotiri S, Bodo E, Hagen E, Biro T, Arck PC, Paus R: Probing the effects of stress mediators on the human hair follicle: substance P holds central position. Am J Pathol 2007;171:1872-1886.

- 115 Takeda H, Katagata Y, Kondo S: Immunohistochemical study of angiotensin receptors in human anagen hair follicles and basal cell carcinoma. Br J Dermatol 2002;147: 276-280.

116 Slominski A, Pisarchik A, Tobin DJ, Mazurkiewicz JE, Wortsman J: Differential expression of a cutaneous corticotropin-releasing hormone system. Endocrinology 2004;145: 941-950.

-117 Simard M, Manthos H, Giaid A, Lefebvre Y, Goodyer CG: Ontogeny of growth hormone receptors in human tissues: an immunohistochemical study. J Clin Endocrinol Metab 1996;81:3097-3102.

118 Ito N, Ito T, Kromminga A, Bettermann A, Takigawa M, Kees F, Straub RH, Paus R: Hu- man hair follicles display a functional equivalent of the hypothalamic-pituitary-adrenal axis and synthesize cortisol. FASEB J 2005; 19:1332-1334.

119 Smith TM, Cong Z, Gilliland KL, Clawson GA, Thiboutot DM: Insulin-like growth factor-1 induces lipid production in human SEB-1 sebocytes via sterol response elementbinding protein-1. J Invest Dermatol 2006; 126:1226-1232.

120 Hagstromer L, Emtestam L, Stridsberg M, Talme T: Expression pattern of somatostatin receptor subtypes 1-5 in human skin: an immunohistochemical study of healthy subjects and patients with psoriasis or atopic dermatitis. Exp Dermatol 2006;15:950957.

121 Lu ZF, Cai SQ, Wu JJ, Zheng M: Biological characterization of cultured dermal papilla cells and hair follicle regeneration in vitro and in vivo. Chin Med J (Engl) 2006;119: 275-281.

122 Hayman JA, Danks JA, Ebeling PR, Moseley JM, Kemp BE, Martin TJ: Expression of parathyroid hormone related protein in normal skin and in tumours of skin and skin appendages. J Pathol 1989;158:293-296.

123 Muller FB, Muller-Rover S, Korge BP, Kapas S, Hinson JP, Philpott MP: Adrenomedullin: expression and possible role in human skin and hair growth. Br J Dermatol 2003;148: 30-38.

124 Bodo E, Kromminga A, Funk W, Laugsch M, Duske U, Jelkmann W, Paus R: Human hair follicles are an extrarenal source and a nonhematopoietic target of erythropoietin. FASEB J 2007;21:3346-3354.

125 Iguchi M, Aiba S, Yoshino Y, Tagami H: Human follicular papilla cells carry out nonadipose tissue production of leptin. J Invest Dermatol 2001;117:1349-1356.

126 Misumi Y, Akiyoshi T: Consistently nonoverlapping distribution of epidermal growth factor receptors in adult human skin detected by various monoclonal antibodies. Acta Anat (Basel) 1990;137:202-207.

127 Stenn KS, Paus R: Controls of hair follicle cycling. Physiol Rev 2001;81:449-494.

128 Takenaka H, Yasuno H, Kishimoto S: Immunolocalization of fibroblast growth factor receptors in normal and wounded human skin. Arch Dermatol Res 2002;294: 331-338.

129 Kozlowska U, Blume-Peytavi U, Kodelja V, Sommer C, Goerdt S, Majewski S, Jablonska S, Orfanos CE: Expression of vascular endothelial growth factor (VEGF) in various compartments of the human hair follicle. Arch Dermatol Res 1998;290:661-668.

130 Venencie PY, Meduri G, Pissard S, Jolivet A, Loosfelt H, Milgrom E, Misrahi M: Luteinizing hormone/human chorionic gonadotrophin receptors in various epidermal structures. Br J Dermatol 1999;141:438-446.

131 Pelletier G, Ren L: Localization of sex steroid receptors in human skin. Histol Histopathol 2004;19:629-636. 
132 Sohn KC, Jang S, Choi DK, Lee YS, Yoon TJ, Jeon EK, Kim KH, Seo YJ, Lee JH, Park JK, Kim CD: Effect of thioredoxin reductase 1 on glucocorticoid receptor activity in human outer root sheath cells. Biochem Biophys Res Commun 2007;356:810-815.

133 Kenouch S, Lombes M, Delahaye F, Eugene E, Bonvalet JP, Farman N: Human skin as target for aldosterone: coexpression of mineralocorticoid receptors and 11 beta-hydroxysteroid dehydrogenase. J Clin Endocrinol Metab 1994;79:1334-1341.

134 Demay MB, MacDonald PN, Skorija K, Dowd DR, Cianferotti L, Cox M: Role of the vitamin $\mathrm{D}$ receptor in hair follicle biology. J Steroid Biochem Mol Biol 2007;103:344346.
135 Dobrosi N, Toth BI, Nagy G, Dozsa A, Geczy T, Nagy L, Zouboulis CC, Paus R, Kovacs L, Biro T: Endocannabinoids enhance lipid synthesis and apoptosis of human sebocytes via cannabinoid receptor-2-mediated signaling. FASEB J 2008;22:3685-3695.

136 Colombe L, Vindrios A, Michelet JF, Bernard BA: Prostaglandin metabolism in human hair follicle. Exp Dermatol 2007;16: 762-769.

137 Colombe L, Michelet JF, Bernard BA: Prostanoid receptors in anagen human hair follicles. Exp Dermatol 2008;17:63-72.

138 Chen W, Yang CC, Sheu HM, Seltmann H, Zouboulis CC: Expression of peroxisome proliferator-activated receptor and CCAAT/ enhancer binding protein transcription factors in cultured human sebocytes. J Invest Dermatol 2003;121:441-447.
139 Heise R, Mey J, Neis MM, Marquardt Y, Joussen S, Ott H, Widerholt T, Kurschat P, Megahed M, Bickers DR, Merk HF, Baron JM: Skin retinoid concentrations are modulated by CYP26AI expression restricted to basal keratinocytes in normal human skin and differentiated 3rd skin models. J Invest Dermatol 2006;126:2473-2480.

140 Russell LE, Harrison WJ, Bahta AW, Zouboulis CC, Burrin JM, Philpott MP: Characterization of liver $\mathrm{X}$ receptor expression and function in human skin and the pilosebaceous unit. Exp Dermatol 2007;16: 844-852. 